\title{
Determination Amount of Silymarin and Pharmaceutical Products from Milk Thistle Waste Obtained from Cold Press
}

\author{
Derya Duran ${ }^{1 *}$, Semih Ötleş ${ }^{1}$ Ercüment Karasulu² \\ 1 Graduate School of Natural and Applied Science, Food Engineering, Izmir, Turkey \\ 2 Institue of Health Science, Drug Research and Pharmacokinetic Development and Applied Center, Izmir, Turkey
}

\begin{abstract}
In this study, the compounds that contain active ingredients beneficial for health and disposed from $t$ he fruits of milk thistle which from oil was extracted after cold press was obtained, and end products were provided.

At this stage, total ash, insoluble ash in $\mathrm{HCl}$, loss on drying, foreign matter, heavy metal and microbiology analyses were carried out on the milk thistle waste supplied as seeds. The seeds were treated to cold press, then oil and waste were obtained. Peroxide value, FFA, refractive index, fatty acid composition, saponification and iodine number were investigated in the oil. The waste had silymarin compounds significantly, therefore verification was performed for the quantitation of silymarin active ingredient in the waste. The waste contained up to $2 \%$ silymarin.
\end{abstract}

As a result, a formulation was created for the standardized active ingredient and milk thistle oil, and end product was provided in the form of soft capsule.

Keywords: cold press, milk thistle (Silybum marianum), silymarin, soft capsule

\section{INTRODUCTION}

Silybum marianum (L.) Gaertn (synonym Carduus marianus L.) is known as milk thistle. It belongs to Asteraceae family. It originates from the Mediterranean area. However, it has spread to other countries in Europe, Asia, Australia and both Americas ${ }^{1}$. The primary content of $S$. marianum is the presence of a group of flavonolignans known as silymarin in the pericarp and seed coat ${ }^{2}$. The rate of flavonolignans is usually between $1.5 \%$ and $3.5 \%$ of the fruit weight ${ }^{1}$. Silymarin consists of silybin, isosilybin, silydianin, silychristin, isosilychrystin and isosilybinin $^{1 \cdot 3}$. Since among flavonolignan compounds silybin has detoxificationing

*Corresponding Author: Derya Duran, e-mail: derya.orn@gmail.com (Received 18 September 2018, accepted 11 December 2018) 
properties, it stabilizes the functions of the liver. Therefore, $S$. marianum has been grown for pharmaceutical purposes in some European and Asian countries. In recent years, silymarin has been used in various treatments because of its properties in the medical, pharmaceutical and veterinary fields ${ }^{1,4}$. In addition to their hepatoprotective effect, flavonolignans also have antioxidant, antiinflammatory, antifibrotic, hypolipidemic, neurotrophic and neuroprotective effects $^{3}$. Silymarin is also known with its effects of reducing chemotherapy side effects and protecting against radiotherapy-induced toxicity ${ }^{3,5}$.

Milk thistle has a wide area of usage due to the chemical composition of its fruits and biomasses, and oil yield. Byproducts are produced from silymarin extraction, and these biomass is used in various fields including food, fodder, cosmetic and bioenergy.

Cold press is a simple, ecological and energy-efficient method. For these reasons, it is a more economical technique compared to the other methods ${ }^{6}$ such as solvent extraction and hot press. It has been reported to be the best way to produce high-quality oil. When compared with hot pressing and solvent extraction, its oil yield is lower 7 . Cold press has hence drawn the interest of consumers because of nutritional contents and naturality of the oils ${ }^{8}$. Since no heat treatment and chemical process is used during the cold press process, all beneficial nutritional properties of the raw material are transmitted to the oil. Therefore, cold pressed seed oils have high dietary and sensory properties and contain useful elements with significant chemical properties for health 9,10,11. Cold pressed seed oils contain natural phytochemicals such as tocopherols, fatty acids, sterols and antioxidant phenolic compounds ${ }^{12,13,14,15}$.

Milk thistle seed contained high silymarin levels as it was seen in the literature data. In this study, the seeds were treated to cold press, then oil and waste were obtained. Silymarin remained in the waste, it didin't pass to oil. The quantitation of silymarin active ingredient in the waste analyzed. After that, active ingredients were quantified in a product that was not evaluated as waste, formulations were created for mixture with oil which is rich in its own fatty acids, and the end product was produced as capsule. Based on the data obtain from the study, all necessary quality control analyses were conducted on the plantal waste that was the source of silymarin, the biomass of milk thistle, and extraction of end product by dosing was aimed. 


\section{METHODOLOGY}

\section{Materials}

\section{Seed and oil samples}

Seed samples were supplied from an approved supplier in Konya province. These samples were approved after the relevant quality control analyses. The cold pressing technique was applied with an industrial scale in ZADE VITAL Pharmaceuticals Inc. (200 kg seed/day capacity, single head, 2,2 kW power) cold press machine. The cold pressing procedure was set by a 10-mm exit die, and $40 \mathrm{rpm}$ of screw rotation speed and $40{ }^{\circ} \mathrm{C}$ of exit temperature was used ${ }^{16}$.

\section{Glycerin, gelatine and pure water}

Gelatine was supplied from SEL-JEL Inc. vegetative glycerin from the approved supplier, and pure water from ZADE VITAL Pharmaceuticals Inc. in order to produce soft capsule from the material, namely from the biomass generated after cold press.

\section{Chemicals}

Potassium hydroxide was supplied from T. Baker, nitric acid, hydrogen peroxide, phosphoric acid, methanol was supplied from Sigma-Aldrich, media for microbiology was supplied from VWR companies. Pure water and ultrapure water were used to meet the pharmacopeia requirements.

\section{Methods}

\section{Analysis Performed in the Seed}

\section{Total aflatoxin and ochratoxin analysis}

Eueropean Pharmacopoeia 8.0, 2.8.18 method ${ }^{17}$ and Eueropean Pharmacopoeia 8.o, 2.8.22 method $^{17}$ were used for aflatoxin and ochratoxin analyses respectively.

\section{Heavy Metal Analysis}

The analysis is made with Shimadzu / ICPE 9000 device. Burner unit temperature is as follows: Process temperature was gradually increased for 15 minutes up to $200^{\circ} \mathrm{C}$. At the end of this period, the temperature was fixed at $200^{\circ} \mathrm{C}$ for 15 minutes. Then, it was conditioned to cool after the process of 30 minutes. Argon gas was used in ICPE 9000 device conditions. The cooler temperature was set at $-15^{\circ} \mathrm{C}$, and the gas pressure at $450-460$ Pa. Nitric acid of $1 \%$ was prepared. Reference standard solution was prepared as 1, 5, 10, 20, 50, and $100 \mathrm{ppb}$. At the application steps, $0.5 \mathrm{~g}$ sample was weighed in weighing bottle 
on an assay balance. Then the sample was taken to the burner unit container. $7 \mathrm{~mL}$ nitric acid and $1 \mathrm{~mL}$ hydrogen peroxide were added into the container ${ }^{17}$.

\section{The Analysis of Total Ash, Insoluble Ash in HCl, Loss on dryimg, and Foreign Matter}

Because all these analyses were performed under the title of the control of vegetable drugs, European Pharmacopoeia methods were used ${ }^{17}$. The total ash was analyzed using EP 2.4.16, insoluble ash in HCl EP 2.8.1, loss on drying EP 2.2.32, and foreign matter EP 2.8.2 methods.

\section{Microbiological Analysis}

Since microbiology analyses in the seed were made based on drug control, the total bacteria, total yeast and mold, bile tolerant gram-negative bacteria, Escherichia Coli and Salmonella strains specified in European Pharmacopoeia were taken into close scrutiny. All these analyses are made according to EP 2.6.12 and 2.6.13 methods ${ }^{17}$.

\section{Oil Analyses}

\section{Analyses of Peroxide Value, FFA, Saponification Number, Amount of Unsaponifiable Matter and Iodine Number}

After oil extraction from the seed the resultant waste and milk thistle oil provide of end product. For this reason, analyses in the pharmacopoeia is also carried out in milk thistle ${ }^{17}$. These analyses include peroxide value using EP 2.5.5, free fatty acids (FFA) value EP 2.5.1, saponification number EP 2.5.6, amount of unsaponifiable matter EP 2.5.7, and iodine number EP 2.5.4 methods.

\section{Fatty Acid Composition}

Fatty acid composition was made with a validated method in the company. Oil sample of $60 \mathrm{mg}$ was weighed and put into a screwed covered tube then $2 \mathrm{~mL}$ $2 \mathrm{~N}$ methanolic potassium hydroxide solution $(\mathrm{KOH})$ was added on it. It was then mixed with a vortex for 5 minutes after that, $2 \mathrm{~mL}$ of $\mathrm{n}$-Heptane was added on the oil sample and methanolic potassium hydroxide mixture and mixed for 1 minute with the vortex. The oil sample mixed with vortex was centrifuged at $3000 \mathrm{rpm}$ for 5 minutes. Supernatant (organic phase) of the centrifuged sample was taken, filtered and transferred into a GC vial. Schimadzu GC and SUPELCO SP 2560 column were used. Fatty acid was identified using FAMEMIX 37 standard.

Furnace temperature was kept at $140^{\circ} \mathrm{C}$ for 5 minutes. The temperature was raised to $240^{\circ} \mathrm{C}$ with $4^{\circ} \mathrm{C}$ increase per minute and kept for 20 minutes. The 
sample of $1 \mu \mathrm{L}$ was injected. Flow rate was set at $1.1 \mathrm{~mL} / \mathrm{min}$ and nitrogen gas was used as the carrier gas. The analysis lasts 50 minutes. Percentile fatty acid composition was obtained after 50 minutes.

\section{Capsule Analysis}

\section{Disintegration test}

One capsule was put into 6 tubes. Each tube was added a disk. Pure water was used for the fluid medium to be immersed. Fluid medium temperature had to be kept at $37 \pm 2^{\circ} \mathrm{C}$. The equipment was run for 30 minutes. After the time determined for the control of disintegration duration was up, the reservoirs in which the tubes were inserted were removed from the immersed fluid.

\section{Uniformity of dosage units}

Twenty soft gelatine capsules were obtained. At first, each filled capsule was weighed, then the capsule was cut with a knife and the matter in it was removed, and then the capsule was irrigated with chloroform, dried, and the empty gelatine was weighed. The weight difference between the filled and empty states of the capsule was calculated, and the weight of the vegetative preparation in the capsule was found.

\section{Verification of the waste}

\section{Verification of silymarin and its components}

In this study, the active ingredient should be quantified for the dose adjustment of the milk thistle waste used in its finished dosage form. Therefore, since milk thistle was found in the United States Pharmacopoeia, the verification of the active ingredient was carried out.

The used reactives were methanol and phosphoric acid, the used standard Milk Thistle Extract (E.P) and the used placebo was milk thistle waste supplied from ZADE VITAL. The acceptability criteria were considered as RSD\% value $\leq$ 2.0.

Mobile phase: According to the USP 54.2 analysis method, the mobile phase was prepared as two separate phases as Mobile phase A and Mobile phase B. For the mobile phase A, $400.0 \mathrm{~mL}$ methanol and $1600 \mathrm{~mL}$ ultrapure water were put into the mobile phase bottle of $2000 \mathrm{~mL}$ with measuring cylinder and $10 \mathrm{~mL}$ phosphoric acid was added on it. For mobile phase B, $1600 \mathrm{~mL}$ methanol and $400 \mathrm{~mL}$ ultra pure water were put into the mobile phase bottle with measuring cylinder and on which $10 \mathrm{~mL}$ phosphoric acid was added on it. After the prepared mobile phases were filtered through vacuum, the mobile phase was put into the bottle and degased. $1000 \mathrm{ppm}$ main stock solution, and 
10, 20, 50, 100, and 250 ppm silymarin calibration solutions were prepared ${ }^{30}$.

\section{Linearity}

As the acceptability criteria, $R^{2}$ value should be between $1.00 \geq R^{2} \geq 0.99$. Three injections were made at each of 6 separate concentrations.

\section{Limit of Detection (LOD)}

Signal/noise ratio was calculated. This ratio was expected to be $\geq 3.00$.

\section{Limit of Quantification (LOQ)}

Signal/noise ratio was calculated. This ratio was expected to be $\geq 10.00$

\section{Accuracy}

Each recovery was expected to be between $98.0 \%$ and $102.0 \%$ and RSD value between the injections $<2.00$. The samples of $80 \%, 100 \%$, and $120 \%$ were prepared as three in each, and three injections were made from each one.

\section{Reproducibility}

RSD\% value was expected to be $\leq 2 \%$. Six sample solutions of $100 \%$ were prepared. Three injections were made from each sample.

\section{Repeatability of the Method}

$\mathrm{RSD} \%$ value was expected to be $\leq 2 \%$. Six sequential injections were given from $100 \%$ sample solution. Repeatability values of the methods were given in the following table. The results were appropriate according to the acceptability criteria.

\section{Capsule production}

The vegetable material obtained after cold press of milk thistle oil was ground in the grinder, and then filtered through 250-micron screens and the granule size was standardized. The obtained standardized powder mixture was mixed with lecithin, beeswax and milk thistle oil and the end product was obtained. End product which soft capsule formulation was occured about 1\% lecithin, 2\% beewax, $25 \%$ milk thistle waste powder and $72 \%$ of milk thistle oil.

Statistical analysis: Data collected on proximate composition were analyzed by simple descriptive statistics ${ }^{18}$. 


\section{RESULTS AND DISCUSSION}

\section{Results of milk thistle seed}

In a study by Mehring ${ }^{19}$, total ash amounts were analyzed in various seeds and spices. The total ash values in the anise seed $6 \%$, in the bay leaf $9 \%$, in the caraway $8 \%$, in the cinnamon $5 \%$, in the celery $10 \%$, in the cinnamon $5 \%$, in the carnation $7 \%$, in the coriander $8.5 \%$, in the cumin $9 \%$, in the in the ginger $5 \%$, in the mustard $5 \%$ and in the thyme $14 \%$ were found.

The insoluble ash in $\mathrm{HCl}$ value of Morus nigra seeds were found $5.817 \%$ by Shukla et al. ${ }^{20}$ the amount of insoluble ash in $\mathrm{HCl}$ should not exceed $1 \%$ and loss on drying max. 8\%, according to the Fructus Silybi Mariae monograph in $\mathrm{WHO}^{21}$,

Inorganic residues were found by William ${ }^{22}$ in some spices and seeds as follows; in the chili powder abaout $43.1 \mathrm{mg} / 10 \mathrm{~g}$, in the celery seed $85.7 \mathrm{mg} / 10 \mathrm{~g}$, in the cinnamon $63.4 \mathrm{mg} / 10 \mathrm{~g}$.

According to the analyses that should be made under the Herbal Drugs title of European Pharmacopoeia ${ }^{17}$, total ash, insoluble ash in $\mathrm{HCl}$, loss on drying, foreign matter, total aflatoxin, ochratoxin, heavy metal and microbiology analyses were made. In the analysis, the total ash were found as $4.38 \%$, insoluble ash in $\mathrm{HCl}$ as $0.01 \%$, and loss on drying as $6.38 \%$, while foreign matter, total aflatoxin, and total ochratoxin could not be found. As a result, in this studuy analyses values were found to be in close proximity with other literature values.

Table 1. Physicochemical analyses of milk thistle seeds

\begin{tabular}{lll}
\hline Analysis & Specifications & Results \\
\hline Total ash & Max. 5.00 & $4.38 \%$ \\
Insoluble ash in HCL & Max. 5.00\% & $0,01 \%$ \\
Loss on drying & Max. 10.00\% & $6,83 \%$ \\
Foreign matter & Absent / 100 g & Not detected \\
\hline
\end{tabular}

Another analysis group which were expected to be performed in the seeds was microbiological controls with the following results in Table 2. 
Table 2. Microbiological analysis in milk thistle seeds

\begin{tabular}{|l|l|l|}
\hline Controls & Specifications & Results \\
\hline Total bacteria & Max. $5 \times 10^{4} \mathrm{CFU} / \mathrm{g}$ & Conforms \\
\hline Total yeast and mould & Max. $5 \times 10^{2} \mathrm{CFU} / \mathrm{g}$ & Conforms \\
\hline Bile-tolerant gram-negative bacteria & Max. $5 \times 10^{2} \mathrm{CFU} / \mathrm{g}$ & Conforms \\
\hline Escherichia coli & Absent $/ \mathrm{g}($ Absent $/ \mathrm{g})$ & Conforms \\
\hline Salmonella & Absent $/ 25 \mathrm{~g}($ Absent $/ 25 \mathrm{~g})$ & Conforms \\
\hline Aflatoxin & Max. $5.0 \mu \mathrm{g} / \mathrm{kg}$ & Not detected \\
\hline Ochratoxin & Max. $10.0 \mu \mathrm{g} / \mathrm{kg}$ & Not detected \\
\hline
\end{tabular}

Turkish Food Codex Contaminant Statement and the mean of relevant values were considered when acceptability criteria were sought in the seed in heavy metals, and the limit was found as $0.10 \mathrm{mg} / \mathrm{kg}$, while no limit was detected in mercury and cadmium as specification of it should not contain.

In a study ${ }^{23}$, concentration of metals (aluminum, arsenic, lead, and cadmium) was examined using atomic absorption spectrophotometry in medicinal plants including: Thymus vulgaris, Melissa officinalis, Achillea millefolium, Rosmarinus officinalis, and Salvia officinalis around Arak city/Iran. The minimum and maximum levels of toxic metals in these plants was reported to be $3.022 \mu \mathrm{g} / \mathrm{g}$ and $0.254 \mu \mathrm{g} / \mathrm{g}$ for lead and $0.031 \mu \mathrm{g} / \mathrm{g}$ and $0.144 \mu \mathrm{g} / \mathrm{g}$ for cadmium, respectively.

Table 3. Heavy metal analysis in milk thistle seeds

\begin{tabular}{|l|l|l|}
\hline Controls & Specifications & Results \\
\hline Lead & Max. $0.10 \mathrm{mg} / \mathrm{kg}$ & Not detected \\
\hline Mercury & Absent/g & Not detected \\
\hline Cadmium & Absent/g & Not detected \\
\hline
\end{tabular}

Given all these analysis results, milk thistle seed complies with all acceptability criteria as a vegetable drug. 


\section{Results of the analysis of milk thistle seed oil}

In a study by Iman Nasrollahi ${ }^{24}$ peroxide values were respectively found as 0.51 , $0.69,0.68$ and 0.57 , and refractive index values as 1.4646, 1.46482, 1.4656, and 1.4651 in four separate milk thistle oils. In the present study, peroxide value was found as $1.16 \mathrm{meqO}_{2} / \mathrm{kg}$ oil, and refractive index as 1.46 . In a study by Faiza et al. ${ }^{24}$; saponification number was found as $126.2 \mathrm{mg} \mathrm{KOH} / \mathrm{g}$, number of free fatty acids (FFA) as $2.53 \mathrm{mg} / \mathrm{g}$, iodine number as $2.79 \mathrm{mg} / \mathrm{g}$ and specific weight as 0.8129 . In a study by Meddeb $^{21}$; refractive index was found as 1.47, specific weight as $0.91 \mathrm{~g} / \mathrm{mL}$, acidic value as $5.48 \mathrm{mgKOH} / \mathrm{g}$ oil, peroxide values as $2.83 \mathrm{meqO}_{2} / \mathrm{kg}$ oil, iodine number as $112.41 \mathrm{mgKOH} / \mathrm{g}$ oil, and amount of unsaponifiable matter as 1.57. In our study, peroxide value ( $\mathrm{moqO}_{2} / \mathrm{kg}$ oil) was found as 1.16, FFA (in terms of oleic acid) $(\%)(\mathrm{m} / \mathrm{m})$ as 1.70 , amount of unsaponifiable matter $(\mathrm{g} / \mathrm{kg})$ as 14.14 , saponification number $(\mathrm{mgKOH} / \mathrm{g}$ oil) as 200.13, iodine number $\left(\mathrm{mgKOH} / \mathrm{g}\right.$ oil) as 118.03 , refractive index $\left(40^{\circ} \mathrm{C}\right)$ as 1.46 , and specific weight $(\mathrm{g} / \mathrm{mL})\left(20^{\circ} \mathrm{C}\right)$ as 0.92 . Therefore, our results were close to those of the previous studies.

Table 4. Physicochemical analysis of milk thistle oil

\begin{tabular}{|l|l|}
\hline Analysis & Results \\
\hline Peroxide (meq $\mathrm{O}_{2} / \mathrm{kg}$ oil) & 1.16 \\
\hline FFA (in terms of oleic acid) $(\%)(\mathrm{m} / \mathrm{m})$ & 1.70 \\
\hline Amount of unsaponifiable matter $(\mathrm{g} / \mathrm{kg})$ & 14.14 \\
\hline Saponification Number $(\mathrm{mg} \mathrm{KOH} / \mathrm{g}$ oil) & 200.12 \\
\hline lodine Number $(\mathrm{mg} \mathrm{KOH} / \mathrm{g}$ oil) & 118.03 \\
\hline Refractive Index $\left(40^{\circ} \mathrm{C}\right)$ & 1.46 \\
\hline Concentration $(\mathrm{gr} / \mathrm{mL})\left(20^{\circ} \mathrm{C}\right)$ & 0.92 \\
\hline
\end{tabular}


Table 5. Fatty acid composition of milk thistle

\begin{tabular}{|l|l|l|}
\hline Carbon Number & Fatty Acid & Percentage (\%) value \\
\hline C 14:0 & Myristic Acid & 0.06 \\
\hline C 16:0 & Palmitic Acid & 7.75 \\
\hline C 16:1 & Palmitoleic Acid & 0.05 \\
\hline C 18:0 & Stearic Acid & 5.07 \\
\hline C $18: 1$ & Oleic Acid & 23.91 \\
\hline C 18:2 & Linoleic Acid & 55.49 \\
\hline C 20:0 & Arachidic Acid & 3.18 \\
\hline C 20:1 & Gondoic Acid & 0.86 \\
\hline C $18: 3$ & Linolenic Acid & 0.42 \\
\hline C 22:0 & Behenic Acid & 2.30 \\
\hline C 22:1 & Erucic Acid & 0.10 \\
\hline
\end{tabular}

In another study ${ }^{25}$, nine fatty acids were detected. Linoleic acid (18:2n-6) was the dominant fatty acid, it was followed by oleic (18:1n-9), palmitic acid (16:0) and stearic (18:0) acid. The amount of polyunsaturated fatty acid was about $50-54 \%$, and amount of saturated fatty acid was about $19-21 \%$ in the extracted milk thistle oil.

Herein, the important point was that polyunsaturated fatty acids play an important role in cellular communication, membrane structure, prostaglandin synthesis, nervous, endocrine and immune systems ${ }^{26}$.

In study by Iman Nasrollah ${ }^{27}$; fatty acid compositions were studied in 4 different milk thistle oil; and palmitic acid (16:0) was respectively found as $8.55 \%$, 8.36\%, 7.99\% and 9.26\%; stearic acid (18:0) as 5.609\%, 7.72\%, 5.607\% and 5.01\%; oleic acid (18:1) as 28.68\%, 35.85\%, 28.54\%, and 30.42\%, while linoleic acid (18:2) was found as $54.5 \%, 43.57 \%, 54.71 \%$, and $52.78 \%$ and finally linolenic acid (18:3) as 2.50\%, 4.48\%, 3.13\% and $2.51 \%$.

In our study, 11 fatty acids were studied, and the results were given in Table 5. Main results included palmitic acid (16:0) as 7.75\%, stearic acid (18:0) as $5.07 \%$, oleic acid (18:1) as $23.91 \%$, linoleic acid (18:2) as 55.49\%, and arachidic acid (20:0) as $3.18 \%$. In conclusion, milk thistle oil is rich in polyunsaturated fatty acids. 


\section{Results of the analysis of end product soft capsule}

\section{Disintegration time}

In a study by Gurley et al.$^{28}$ disintegration time of milk thistle oil soft capsule was found as 12.6 minutes. It has a total daily dose of $440 \mathrm{mg}$.

In another study ${ }^{29}$, disintegration times were studied in different soft capsules. Disintegration time was found as 9.7 minutes in amantadine soft capsule at covered room temperature, considering storage conditions, and the time increased to 10 minutes 2 weeks after room temperature, and 10.3 minutes after 2 further weeks at $40^{\circ} \mathrm{C}$. When the same processes were made in flaxseed oil soft capsule; again the disintegration time was found as 8.2 minutes at room temperature, 7.7 minutes 2 weeks after the storage, and 8.3 minutes after 2 weeks at $40^{\circ} \mathrm{C}$. The same studies were conducted in soy oil, and ginseng soft capsules. In our soft capsule that we produced with milk thistle waste and milk thistle oil, disintegration time was found as 13 minutes at $37 \pm 2{ }^{\circ} \mathrm{C}$.

\section{Uniformity of dosage units}

Because milk thistle substance was in the range of 90-110\% 'Milk Thistle Capsule Monograph' title of USP $38 \mathrm{NF} 33^{30}$, we predicted an amount of vegetative preparation in the range of 810-990 based on the capsules of $900 \mathrm{mg}$. For this purpose, 20 capsules were selected and analyzed. The mean capsule value was about $900 \mathrm{mg}$, and this value was within the limits.

\section{Verification of active ingredients in the waste}

The analysis was conducted using the Powder Milk Thistle method in USP. Verification procedure was applied since the method was registered in American United States Pharmacopeia (USP) ${ }^{30}$. Within the verification, following parameters was analyzed.

- Linearity

- Limit of Detection (LOD)

- Limit of Quantification (LOQ)

- Accuracy

- Reproducibility

- Repeatability

The results for linearity was summarized in the following Table 6 . 
Table 6. Accuracy values for total silymarin

\begin{tabular}{|c|c|c|c|c|c|}
\hline $\begin{array}{c}\text { Sample } \\
\text { No }\end{array}$ & $\begin{array}{c}\text { Theoretical } \\
\text { Concentration } \\
(\%)\end{array}$ & $\begin{array}{c}\text { Concentration } \\
(\mathrm{mg} / \mathrm{mL})\end{array}$ & $\begin{array}{c}\text { Peak Areas } \\
(\mathrm{mAU} * \mathrm{~s})\end{array}$ & $\begin{array}{c}\text { Mean Peak } \\
\text { Areas } \\
\left(\mathrm{mAU}^{*} \mathrm{~s}\right)\end{array}$ & RSD $\%$ \\
\hline \multirow{3}{*}{1} & \multirow{3}{*}{25} & \multirow{3}{*}{0,025} & 408713,0 & \multirow{3}{*}{407872,00} & \multirow{3}{*}{1,16} \\
\hline & & & 402782,0 & & \\
\hline & & & 412121,0 & & \\
\hline \multirow{3}{*}{2} & \multirow{3}{*}{75} & \multirow{3}{*}{0,075} & 1112058,0 & \multirow{3}{*}{1125253,33} & \multirow{3}{*}{1,06} \\
\hline & & & 1135179,0 & & \\
\hline & & & 1128523,0 & & \\
\hline \multirow{3}{*}{3} & \multirow{3}{*}{100} & \multirow{3}{*}{0,100} & 1465893,0 & \multirow{3}{*}{1477306,00} & \multirow{3}{*}{1,14} \\
\hline & & & 1496567,0 & & \\
\hline & & & 1469458,0 & & \\
\hline \multirow{3}{*}{4} & \multirow{3}{*}{150} & \multirow{3}{*}{0,150} & 2223280,0 & \multirow{3}{*}{2210673,33} & \multirow{3}{*}{0,84} \\
\hline & & & 2219508,0 & & \\
\hline & & & 2189232,0 & & \\
\hline \multirow{3}{*}{5} & \multirow{3}{*}{200} & \multirow{3}{*}{0,200} & 3166932,0 & \multirow{3}{*}{3188459,00} & \multirow{3}{*}{0,59} \\
\hline & & & 3197370,0 & & \\
\hline & & & 3201075,0 & & \\
\hline \multirow{3}{*}{6} & \multirow{3}{*}{250} & \multirow{3}{*}{0,250} & 4025934,0 & \multirow{3}{*}{4036681,67} & \multirow{3}{*}{0,23} \\
\hline & & & 4043571,0 & & \\
\hline & & & 4040540.0 & & \\
\hline
\end{tabular}

\begin{tabular}{|c|c|}
\hline \multicolumn{2}{|c|}{ STATISTICAL EVALUATION } \\
\hline Correlation Factor $\left(\mathrm{R}^{2}\right)$ & 0,9961 \\
\hline Slope & 16230 \\
\hline Intercept & 89617 \\
\hline
\end{tabular}

Silymarin solution was prepared at 6 different concentrations of 25, 75, 100, 150, 200, and $25 \mathrm{ppm}$ for linearity among the verification parameters. A linear chart was obtained according to device result, area values, and equation of $\mathrm{y}=$ $\mathrm{ax}+\mathrm{b}$ (Chart 1). Again, recovery percentage (RSD\%) was found as $\leq 2$. 
Tablo 7. Accuracy values for silymarin.

\begin{tabular}{|c|c|c|c|c|c|c|}
\hline $\begin{array}{c}\text { Sample } \\
\text { No }\end{array}$ & $\begin{array}{l}\text { Concentration } \\
(\mathrm{mg} / \mathrm{mL})\end{array}$ & $\begin{array}{c}\text { Peak Areas } \\
\left(\mathrm{mAU}{ }^{*} \mathrm{~s}\right)\end{array}$ & $\begin{array}{c}\text { Mean Areas } \\
\left(\mathrm{mAU}{ }^{*} \mathrm{~s}\right)\end{array}$ & $\begin{array}{c}\text { Recovery } \\
(\%)\end{array}$ & $\begin{array}{c}\text { Mean } \\
\text { Recovery } \\
(\%)\end{array}$ & $\%$ RSD \\
\hline \multirow{3}{*}{1} & \multirow{3}{*}{0,080} & 3014038,0 & \multirow{3}{*}{3008264,00} & \multirow{3}{*}{100,64} & \multirow{9}{*}{99,66} & \multirow{9}{*}{1,39} \\
\hline & & 3055221,0 & & & & \\
\hline & & 2955533,0 & & & & \\
\hline \multirow{3}{*}{2} & \multirow{3}{*}{0,080} & 3005572,0 & \multirow{3}{*}{2929789,67} & \multirow{3}{*}{98,06} & & \\
\hline & & 2937406,0 & & & & \\
\hline & & 2846391,0 & & & & \\
\hline \multirow{3}{*}{3} & \multirow{3}{*}{0,080} & 2947268,0 & \multirow{3}{*}{2997371,00} & \multirow{3}{*}{100,28} & & \\
\hline & & 3084160,0 & & & & \\
\hline & & 2960685,0 & & & & \\
\hline \multirow{3}{*}{4} & \multirow{3}{*}{0,100} & 3805910,0 & \multirow{3}{*}{3814293,33} & \multirow{3}{*}{101,66} & \multirow{9}{*}{101,65} & \multirow{9}{*}{0,20} \\
\hline & & 3819263,0 & & & & \\
\hline & & 3817707,0 & & & & \\
\hline \multirow{3}{*}{5} & \multirow{3}{*}{0,100} & 3834192,0 & \multirow{3}{*}{3821254,00} & \multirow{3}{*}{101,84} & & \\
\hline & & 3832395,0 & & & & \\
\hline & & 3797175,0 & & & & \\
\hline \multirow{3}{*}{6} & \multirow{3}{*}{0,100} & 3788289,0 & \multirow{3}{*}{3806295,33} & \multirow{3}{*}{101,45} & & \\
\hline & & 3809254,0 & & & & \\
\hline & & 3821343,0 & & & & \\
\hline \multirow{3}{*}{7} & \multirow{3}{*}{0,120} & 4449077,0 & \multirow{3}{*}{4532777,67} & \multirow{3}{*}{100,43} & & \\
\hline & & 4457120,0 & & & & \\
\hline & & 4692136,0 & & & & \\
\hline & & 4464181,0 & & & & \\
\hline 8 & 0,120 & 4513701,0 & 4492095,33 & 99,54 & 100,41 & 0,72 \\
\hline & & 4498404,0 & & & & \\
\hline & & 4498404,0 & & & & \\
\hline 9 & 0,120 & 4690313,0 & 4571194,67 & 101,27 & & \\
\hline & & 4524867,0 & & & & \\
\hline
\end{tabular}

\begin{tabular}{|c|c|}
\hline \multicolumn{2}{|c|}{ STATISTICAL EVALUATION } \\
\hline MEAN RECOVERY \% & 100,01 \\
\hline STANDARD DEVIATION & 0,90 \\
\hline RSD $\%$ & 0,90 \\
\hline
\end{tabular}


For accuracy parameters, each recovery was between $98.0 \%$ and 102.0\%, and RSD value was $<2.00 \%$. The samples of $80 \%, 100 \%$, and $120 \%$ were prepared as three in each, and three injections were made from each one.

Table 8. Total silymarin recovery values

\begin{tabular}{|c|c|c|c|c|c|}
\hline $\begin{array}{c}\text { Sample } \\
\text { No }\end{array}$ & $\begin{array}{l}\text { Concentration } \\
(\mathrm{mg} / \mathrm{ml})\end{array}$ & $\begin{array}{c}\text { Peak Areas } \\
\left(\mathrm{mAU}{ }^{*} \mathrm{~s}\right)\end{array}$ & $\begin{array}{l}\text { RSD } \\
(\%)\end{array}$ & $\begin{array}{c}\text { Mean Area } \\
\left(\mathrm{mAU}^{*} \mathrm{~s}\right)\end{array}$ & Recovery (\%) \\
\hline \multirow{3}{*}{1} & \multirow{3}{*}{0,100} & 1487466,5 & \multirow{3}{*}{0,39} & \multirow{3}{*}{1487223,83} & \multirow{3}{*}{99,60} \\
\hline & & 1481366,5 & & & \\
\hline & & 1492838,5 & & & \\
\hline \multirow{3}{*}{2} & \multirow{3}{*}{0,100} & 1474817,5 & \multirow{3}{*}{1,77} & \multirow{3}{*}{1471510,83} & \multirow{3}{*}{98,51} \\
\hline & & 1495767,5 & & & \\
\hline & & 1443947,5 & & & \\
\hline \multirow{3}{*}{3} & \multirow{3}{*}{0,100} & 1488724,5 & \multirow{3}{*}{0,60} & \multirow{3}{*}{1488637,50} & \multirow{3}{*}{99,69} \\
\hline & & 1497576,5 & & & \\
\hline & & 1479611,5 & & & \\
\hline \multirow{3}{*}{4} & \multirow{3}{*}{0,100} & 1489920,5 & \multirow{3}{*}{0,68} & \multirow{3}{*}{1494016,83} & \multirow{3}{*}{100,07} \\
\hline & & 1486511,5 & & & \\
\hline & & 1505618,5 & & & \\
\hline \multirow{3}{*}{5} & \multirow{3}{*}{0,100} & 1471985,5 & \multirow{3}{*}{1,48} & \multirow{3}{*}{1497598,83} & \multirow{3}{*}{100,31} \\
\hline & & 1509519,5 & & & \\
\hline & & 1511291,5 & & & \\
\hline \multirow{3}{*}{6} & \multirow{3}{*}{0,100} & 1471832,5 & \multirow{3}{*}{0,54} & \multirow{3}{*}{1472499,17} & \multirow{3}{*}{98,58} \\
\hline & & 1480743,5 & & & \\
\hline & & 1464921,5 & & & \\
\hline
\end{tabular}

\begin{tabular}{|c|c|}
\hline \multicolumn{2}{|c|}{ STATISTICAL EVALUATION } \\
\hline MEAN RECOVERY \% & 99,46 \\
\hline STANDARD DEVIATION & 0,75 \\
\hline RSD \% & 0,76 \\
\hline
\end{tabular}

Recovery values from $100 \%$ concentration were found between $98 \%$ and $102 \%$, indicating the method worked correctly. 
Table 9. Total silymarin repeatability values

\begin{tabular}{|c|c|}
\hline SAMPLE & AREA (mAU*s) \\
\hline 1 & 1502274,5 \\
\hline 2 & 1492981,5 \\
\hline 3 & 1488446,5 \\
\hline 4 & 1489787,5 \\
\hline 5 & 1492166,5 \\
\hline 6 & 1491073,5 \\
\hline Mean & 1492788,33 \\
\hline RSD \% & 0,33 \\
\hline
\end{tabular}

Six sequential injections were given from 100\% solution. Area values were highly close to each other, indicating repeatability of the method.

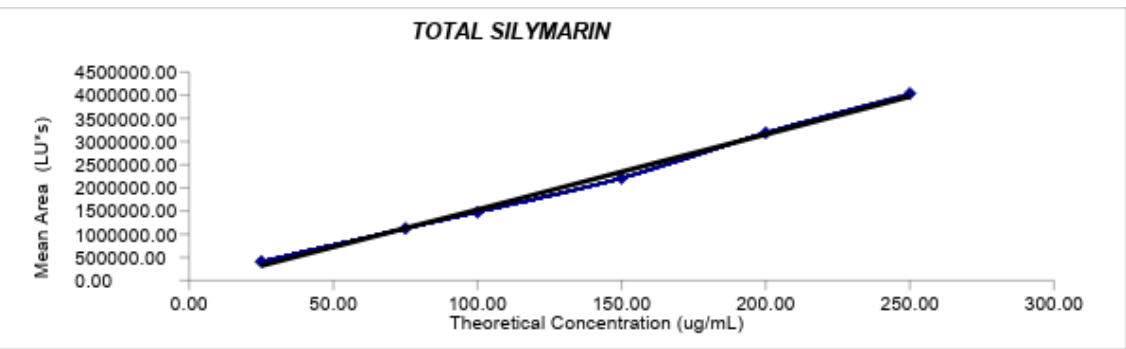

Figure 1. Total silymarin accuracy chart

\section{CONCLUSION AND RECOMMENDATIONS}

Milk thistle is a plant which can easily grow almost all countries worldwide including our country. With flavonolignan compounds named fatty acids and silymarin that it contains in seed and the oil, milk thistle found a wide area of use in many field such as medicine, cosmetic, and food. The oil, rich in polyunsaturated fatty acids were obtained after cold press, but compounds that are named as hepatic protectors especially silymarin are not transported to the oil. They remain in vegetative pomace called waste. In this study, active ingredients were quantified in a product that is not evaluated as waste, formulations were created for mixture with oil which is rich in its own fatty acids, and the end product was produced as capsule. By this way, we aimed to produce a standardized product, and obtained a value-added product from waste material. Thus, we demonstrated that this product which we made pilot test at laboratory scale can be produced at industry scale. 


\section{ACKNOWLEDGEMENT}

This study was supported by Zade Vital Pharmaceuticals Inc and by Ege University Coordinatorship of Scientific Research Projects (Project No: 17-MÜH015).

\section{REFERENCES}

1. Morazzoni P., Bombardelli E. Silybum marianum (Carduus marianus). Fitoterapia, 1995, $66,3-42$.

2. Cappelletti E.M., Canaito R. Silymarin localization in the fruit and seed of Silybum marianum (L.) Gaertn. Herba Hungarica, 1984, 23, 53-62.

3. Abenavoli L., Capasso R., Milic N., Capasso F. Milk thistle in liver diseases: past, present, future. Phytotherapy Research, 2010, 24, 1423-1432.

4. Thanonkaew, A., Wongyai, S., McClements, D. J., \& Decker, E. A. Effect of stabilization of rice bran by domestic heating on mechanical extraction yield, quality, and antioxidant properties of cold-pressed rice bran oil (Oryza saltiva L.). LWT-Food science and technology, 2012, 48(2), 231-236.

5. Meddeb W., Rezing L., Abderrabba M., Lizard G., Mejri M., Tunisian Milk Thistle: An Investigation of the Chemical Composition and the Characterization of Its Cold-Pressed Seed Oils. Int. J. Mol. Sci., 2017, 18, 2582.

6. Radko L., Cybulski W. Application of silymarin in human and animal medicine. Journal of Pre-Clinical and Clinical Research, 2007, 1, 22-26.

7. Yilmaz, E., Aydeniz, B., Guneser, O., \& Arsunar, E. S. Sensory and Physico-Chemical Properties of Cold Press-Produced Tomato (Lycopersicon esculentum L.) Seed Oils. Journal of the American Oil Chemists' Society, 2015, 92(6), 833-842.

8. Thanonkaew, A., Wongyai, S., McClements, D. J., \& Decker, E. A., Effect of stabilization of rice bran by domestic heating on mechanical extraction yield, quality, and antioxidant properties of cold-pressed rice bran oil (Oryza saltiva L.). LWT-Food science and technology, 2012, 48(2), 231-236.

9. Argon Z., \& Gokyer A. Determination of Physicochemical Properties of Nigella sativa Seed Oil from Balıkesir Region, Turkey, Chemical and Process Engineering Research, 2016, 41, 43-46.

10. Gharibzahedi, S. M. T., Mousavi, S. M., Hamedi, M., Rezaei, K., \& Khodaiyan, F. Evaluation of physicochemical properties and antioxidant activities of Persian walnut oil obtained by several extraction methods. Industrial crops and products, 2013, 45, 133-140.

11. Topkafa, M. Evaluation of chemical properties of cold pressed onion, okra, rosehip, safflower and carrot seed oils: triglyceride, fatty acid and tocol compositions. Analytical Methods, 2016, 8(21), 4220-4225.

12. Bozan, B., \& Temelli, F. Chemical composition and oxidative stability of flax, safflower and poppy seed and seed oils. Bioresource Technology, 2oo8, 99(14), 6354-6359.

13. Lutterodt, H., Slavin, M., Whent, M., Turner, E., \& Yu, L. L. Fatty acid composition, oxidative stability, antioxidant and antiproliferative properties of selected cold-pressed grape seed oils and flours. Food Chemistry, 2011, 128(2), 391-399. 
14. Gumus, Z. P., Guler, E., Demir, B., Barlas, F. B., Yavuz, M., Colpankan, D., \& Timur, S. Herbal infusions of black seed and wheat germ oil: Their chemical profiles, in vitro bio-investigations and effective formulations as phyto-nanoemulsions. Colloids and Surfaces B: Biointerfaces, 2015, 133, 73-80.

15. Kozłowska, M., Gruczyńska, E., Ścibisz, I., \& Rudzińska, M. Fatty acids and sterols composition, and antioxidant activity of oils extracted from plant seeds. Food chemistry, 2016, $213,450-456$.

16. Yilmaz E, Aydeniz B, Güneser O., Arsunar E.S., Sensory and PhysicoChemical Properties of Cold PressProduced Tomato (Lycopersicon esculentum L.) Seed Oils J Am Oil Chem Soc. 2015, 92, 833-842.

17. European pharmacopoeia, 8rd ed. Council of Europe, 2014.

18. Annongu, A. Azor, Joseph J. K., Proximate Analysis of Castor Seeds And Cake, J. Appl. Sci. Environ. Manage. 2008, 12(1) 39 - 41.

19. A. L. Mehrıng, Total Ash Determination In Spices, Journal of Agricultural Research, 1924, $1181-87$.

20. Shukla R.K., Painuly D., Shukla A., Kumar V., Singh J., Porval A., Vats S., Physical Evaluation, Proximate Analysis and Antimicrobial Activity of Morus Nigra Seeds Int J Pharm Pharm Sci, 2015, 7(1), 191-197.

21. WHO Monographs on Selected Medicinal Plants - Volume 1, 1999.

22. William V. Eisenberg, Inorganic Particle Content of Foods and Drugs Environmental Health Perspectives 1974, Vol. 9, pp. 183-191

23. Fytianos K, Katsianis G, Triantafyllou P, Zachariadis G., Accumulation of heavy metals in vegetables grown in an industrial area in relation to soil. Bulletin of Environmental Contamination And Toxicology. 2001, 67(3), 0423-30.

24. Faiza A, Naveed I R, Noor-Ul-Ain, Uneeza J, Farhat Y. Some Physio-Chemical Properties of Silybum marianum Seed Oil Extract. Curr Trends Biomedical Eng \& Biosci. 2018, 13(5), 555875 .

25. Fathi-Achachlouei B., Azadmard-Damirchi S., Milk Thistle Seed Oil Constituents from Different Varieties Grown in Iran J Am Oil Chem Soc. 2oo9, 86, 643-649.

26. Yehuda S PUFA: mediators for the nervous, endocrine, immune systems. In: Mostofsky DI, Yehuda S, Salem N (eds) Fatty acids: physiological and behavioral functions. Humana, Totowa, 2001, pp 403-420.

27. Nasrollahi I, Talebi1 E, Nemati Z. Study on Silybum marianum Seed through Fatty Acids Comparison, Peroxide Tests, Refractive Index and Oil Percentage. Pharmacognosy Journal. 2016, 8(6), 595-597.

28. Gurley B. J., Barone G. W., Williams D. K., Carrier J., Breen P., Yates R. C., Song P, Hubbard A. M., Tong Y., Cheboyina S. Effect of Milk Thistle (Silybum Marianum) And Black Cohosh (Cimicifuga Racemosa) Supplementation On Digoxin Pharmacokinetics In Humans. American Society for Pharmacology and Experimental Therapeutics, 2005, 34, 69-74.

29. Almukainzi M., Salehi M., Chacra N. A. B., Löbenberg R., Comparison of the Rupture and Disintegration Tests for Soft-Shell Capsules. Dissolution Technologies, 2011, 21-25.

30. United States Pharmacopeia 38 National Formulary 33, 2014. 